\title{
PRESSUPOSTOS TEÓRICOS DA EDUCAÇÃO: ALGUMAS REFLEXÕES HISTÓRICAS
}

\author{
PRESUPUESTOS TEÓRICOS DA LA EDUCACIÓN: ALGUNAS REFLEXIONES \\ HISTÓRICAS
}

\section{THEORETICAL PRESSUPOSITIONS OF EDUCATION: SOME HISTORICAL REFLECTIONS}

\author{
Rodrigo REGERT ${ }^{1}$ \\ Arã Paraguassu RIBEIRO ${ }^{2}$ \\ Everaldo da SILVA ${ }^{3}$ \\ Joel Haroldo BAADE ${ }^{4}$
}

RESUMO: A educação sempre foi tema de muita discussão e ainda continua sendo. Baseado nessa ideia, o presente artigo tem como objetivo discutir os pressupostos teóricos da educação, iniciando com a própria ideia do desenvolvimento intelectual humano e passando pela Idade Antiga, Média, Moderna e Contemporânea. É importante ressaltar que o artigo não tem a pretensão de esgotar toda essa temática, nem mesmo de abordar todos os pressupostos teóricos, o que de fato seria impossível, porém propõe-se a iniciar ou até mesmo continuar essa discussão. Para isso a pesquisa, utilizou-se do método descritivo e o seu procedimento técnico se deu de forma bibliográfica. Conclui-se que é importante discutir sobre os pressupostos teóricos da educação na história, pois sem isso tampouco é possível entender a educação atual.

PALAVRAS-CHAVE: Pressupostos teóricos. Reflexões. Educação. História.

RESUMEN: La educación siempre fue tema de mucha discusión y todavía sigue siendo. Basado en esa idea, el presente artículo tiene por objetivo discutir los presupuestos teóricos de la educación, empezando con la propia idea del desarrollo intelectual humano y pasando por la Edad Antigua, Media, Moderna y Contemporánea. Es importante resaltar que el artículo no tiene la pretensión de agotar toda esa temática, tampoco abordar todos los presupuestos teóricos, lo que de hecho sería imposible, pero se propone a empezar o mismo dar continuidad a esa discusión. Para eso la búsqueda se utilizó del método descriptivo y su procedimiento técnico se dio de forma bibliográfica. Se concluye que es importante discutir sobre los presupuestos teóricos de la educación en la historia, pues sin eso tampoco es posible comprender la educación actual.

${ }^{1}$ Universidade Alto Vale do Rio do Peixe - UNIARP. Mestrando. Programa de Pós-Graduação Interdisciplinar em Desenvolvimento e Sociedade. E-mail: regert.rodrigo@gmail.com.

${ }^{2}$ Universidade Alto Vale do Rio do Peixe - UNIARP. Mestrando. Programa de Pós-Graduação Interdisciplinar em Desenvolvimento e Sociedade. E-mail: araqme@ yahoo.com.br.

${ }^{3}$ Universitário de Brusque - UNIFEBE. Professor Doutor e pesquisador UNIFEBE. E-mail: prof.evesilva@gmail.com.

${ }^{4}$ Universidade Alto Vale do Rio do Peixe - UNIARP. Professor Doutor no Programa de Pós-Graduação Interdisciplinar em Desenvolvimento e Sociedade. E-mail: baadejoel@gmail.com. 
PALAVRAS CLAVE: Presupuestos teóricos. Reflexiones. Educación. Historia.

ABSTRACT: Education has always been a much discussed theme and continues to be so. Based on this idea, the goal of this article is to discuss the theoretical pressupositions of education, beginning with the idea itself of human intellectual development and passing through the Ancient, Medieval, Modern and Contemporary Ages. It is important to point out that the article does not have the intention of covering the whole of this theme, nor even all of the theoretical pressupositions, which would be impossible. But it intends to begin or at least continue this discussion. For this the research made use of the descriptive method and its technical procedures took place in a bibliographic way. We conclude that it is important to discuss the theoretical pressupositions of education in history since, without this, it is not even possible to understand current education.

KEYWORDS: Theoretical pressupositions. Reflections. Education. History.

\section{Introdução}

A história da educação sempre esteve associada à própria ideia da evolução do pensamento humano. A passagem da compreensão da realidade, que era dada através da mitologia para a forma racional de pensamento, talvez seja o grande salto para esse processo.

Desse modo, muitas foram as influências no decorrer da história que permitiram essa discussão, iniciando pela Idade Antiga, Média, Moderna e chegando à Contemporânea, na atualidade.

Por isso, fazer um estudo, retomando alguns dos principais pressupostos teóricos da história que nortearam a educação, parece imprescindível para entender a educação atual e as formas que ela tomou.

Nesse sentido, o presente artigo tem o objetivo de discutir os pressupostos teóricos da educação, iniciando com a própria ideia do desenvolvimento intelectual humano e passando pelos quatro períodos da história. Para isso, no aspecto metodológico a pesquisa utilizou-se do método descritivo, e o seu procedimento técnico se deu de forma bibliográfica.

\section{A educação e seu início}


A educação parece que sempre esteve associada à própria ideia de desenvolvimento intelectual do ser humano. A transição do pensamento mítico para o racional ou filosófico vem ao encontro disso, ao de possibilitar uma maior compreensão da realidade em que o ser humano vivia.

Anterior a isso, "[...] a realidade mítica é o ambiente ou contexto segundo o qual as interpretações servem como pressupostos para a compreensão e a relação que o homem estabelece com a sua realidade" (SCHNEIDER, 2009, p. 26).

Mediante o exposto, fica claro que a realidade era entendida sob o ponto de vista místico. As associações da mesma se davam baseadas nas explicações fabulosas sobre as origens das coisas.

Um mito pode tentar explicar o desconhecido, como a criação da Terra e do universo. $\mathrm{O}$ mito também tenta responder às grandes questões fundamentais que todas as pessoas se fazem sobre o significado e o propósito da existência humana (SEARS, 2015, p. 12).

Um exemplo interessante é como se deu a própria criação do universo. Inicialmente, todos os elementos (terra, céu, mar, ar e água) eram uma única coisa, que fora chamada de Caos, onde uns lutavam contra os outros até que uma força sem nome separou os elementos e os deu forma (SEARS, 2015).

Uma vez separados, os elementos ainda precisavam de forma e definição. Segundo um mito popular, uma força sem nome (alguns chamam-na de Criador) deu forma à Terra. O Criador conduziu a água para os lugares apropriados; e, então, levantou as montanhas, suavizou as planícies e escavou os vales, distribuindo florestas, terrenos rochosos e campos férteis. Em seguida, veio o céu. O Criador espalhou o ar como uma tela em branco. Acrescentou nuvens, trovões, relâmpagos e ventos. As estrelas, porém, foram extraídas dos confins das trevas.

Depois de estabelecer o céu e a Terra, o criador acrescentou os peixes aos mares, os pássaros ao ar e os animais à Terra. Nem todos os animais foram criados nessa época - a humanidade ainda não existia (SEARS, 2015 , p. 24 e 15).

É interessante perceber que essa ideia de criação do universo ajudou a humanidade a sanar seus questionamentos sobre o mesmo por muito tempo, até que num determinado momento não foi mais suficiente. Os questionamentos do ser humano passaram a ser mais elaborados, e para satisfazer suas curiosidades foi necessário ir em outra direção, proporcionando assim o surgimento do logos. 
Logos é uma palavra de origem grega que se refere ao caráter de combinação, associação e ordenação, que passam a dar sentido às coisas por meio da inteligência ou razão humana (JAPIASSÚ; MARCONDES, 2006).

Nesse sentido, o logos se torna responsável para conduzir a humanidade à verdade, onde a filosofia, através do seu método racional, passa orientar o caminho a ser traçado; por isso, a filosofia da educação é que faz com que se perceba a necessidade diária e constante de rever as concepções de educação em construção (SCHNEIDER, 2009).

Retomando a ideia central do primeiro parágrafo, onde foi mencionado que a educação parece que sempre esteve associada à ideia de desenvolvimento intelectual do ser humano, é exatamente isso que se torna claro a partir do momento que ela auxilia na vida do homem e da mulher, interferindo e refletindo sobre a realidade que se apresenta aos mesmos

\section{Pressupostos teóricos da educação na idade antiga}

Iniciando a discussão na história sobre os pressupostos teóricos da educação com vistas para ao mundo Ocidental, o mesmo se inicia com a história da própria civilização grega.

A Idade Antiga, de modo geral, é marcada pelo período que vai desde a origem da civilização grega, aproximadamente a partir do ano 2000 a.C., até a queda definitiva do Império Romano, no ano de 476 d.C., onde os bárbaros liderados por Odoacro invadiram Roma e desfacelaram o império (PEDRO; LIMA; CARVALHO, 2005).

Embora a Idade Antiga tenha sido iniciada aproximadamente a partir do ano 2000 a.C., o primeiro grande pensador que também refletiu sobre a educação foi Sócrates (470/469-399 a.C.); por isso, o surgimento da filosofia e da educação é praticamente concomitante.

Ensinou-nos [...] que para chegar ao conceito de algo é exatamente necessário, como no trabalho manual, exercer a negatividade. Parte-se das imagens múltiplas que se possui de algo, em seguida se inicia o processo negativo: procura-se o que é comum no interior dessa multiplicidade e que deve assim ser preservado; posteriormente, ocorre a divisão: corta-se, como o talhador quebrando a pedra, aquilo que é diverso e inessencial (BENOIT, 1996, p. 8). 
Dessa forma, só se encontra a real superação da diferença a partir do momento que o esforço do negativo é realizado, ou seja, quando se dá a definição ou conceito de algo (BENOIT, 1996).

Para isso, Sócrates utiliza-se de um método chamado de maiêutica, onde o interlocutor parte do princípio que não sabe nada para em seguida poder questionar sobre a lógica dos seus próprios argumentos. Esse é o processo que precisa ser percebido para se ter afirmações mais precisas possíveis, pois somente a multiplicidade das questões é que irá levar o interlocutor à descoberta de suas próprias verdades (SCHNEIDER, 2009).

Nesse sentido é que Sócrates se compara a uma parteira, pois da mesma forma que a parteira ajuda a dar à luz, assim ele o faz com seus alunos, ela auxilia a luz da sabedoria (SCHNEIDER, 2009).

É importante perceber que nesse momento da história os teóricos já estavam auxiliando nos processos educativos, embora, é obvio, que de forma muito rudimentar ainda, pelo menos para a realidade atual, onde essa discussão tem ganhado cada vez mais espaço.

No entanto, aos poucos os teóricos foram se preocupando cada vez mais com a educação. Platão (428/427-347 a.C.), por exemplo, entendia que somente por meio da educação é possível estar aberto ao novo e atualizar as potencialidades: a educação para ele tem como primeira tarefa a humanização, educar um homem faz parte do processo humano (TEIXEIRA, 1999).

Só o homem é um ser educável que consegue conservar e propagar a sua forma de existência por meio da vontade e da razão. O ser humano cria progressivamente a si próprio e cria, pelo conhecimento do mundo exterior e interior, formas melhores de existência humana (TEIXEIRA, 1999, p. 25).

Dentro deste contexto, o ser humano se torna o responsável pela sua criação e propagação. Devido a isso, cabe a ele refletir sobre sua própria espécie e possibilitar formas melhores e mais seguras para o seu desenvolvimento.

Por fim, outro grande importante teórico que refletiu sobre a educação foi Aristóteles (384-322 a.C.); para ele:

O modelo de Aristóteles parte da premissa de que ato e potência, natural e cultural estão interligados. A virtude é entendida como fruto da práticarealismo, e a imitação é vista como princípio da aprendizagem. Desse modo, é fundamentação da educação aprimorar a potência que cada um recebeu da natureza (SCHNEIDER, 2009, p. 85). 
Para Aristóteles, ato é a confirmação das possibilidades, enquanto que potência é a possibilidade que ainda não foi efetivada, por isso, a educação passa a ser um processo monolítico, de manutenção, pois não é idealizada pelo todo, mas apenas por alguns membros da sociedade e não contempla a diversidade existente em cada indivíduo (SCHNEIDER, 2009).

Sendo assim, é importante estar atento ao que Aristóteles menciona, pois parece que a educação era vista como seletiva, onde deixava de contemplar a individualidade dos seres humanos.

\section{Pressupostos teóricos da educação na idade média}

Dando sequência na história, surge a Idade Média, que foi um período marcado pela forte influência da Igreja. Ela inicia quando os bárbaros ${ }^{5}$ invadiram a Itália, no ano de 410, mas se oficializa mais tarde com a invasão à Roma, no ano de 476, e se estende por quase mil anos, tendo seu fim somente em 1453, na Guerra dos Cem Anos (1337-1453), travada entre as realezas inglesa e francesa, com a vitória da francesa, graças ao grande poderio de armas de fogo que derrotou a cavalaria feudal (PEDRO; LIMA; CARVALHO, 2005).

Foi durante a Idade Média que se consolidou o feudalismo, um sistema que se baseava em troca, ou seja: existiam um ou mais senhores feudais que dominavam um determinado território e davam segurança aos camponeses que viviam dentro do feudo, que em troca pagavam uma quantia anual em bens aos senhores feudais; porém, durante a própria Idade Média, esse sistema começa a entrar em decadência (PEDRO; LIMA; CARVALHO, 2005).

Nesse período, a doação de terras e bens feitas pelos senhores feudais fez com que a Igreja acumulasse poderes e riquezas, graças, sobretudo, à influência espiritual que exercia sobre as pessoas. No ano de 455, o chefe da Igreja com sede em Roma passou a se chamar Papa, ou seja, chefe da igreja cristã, enquanto que os restantes do clero tinham a tarefa de converter os bárbaros que invadiam a Europa (PEDRO; LIMA; CARVALHO, 2005).

Diante desse cenário, é evidente que os grandes pensadores da época (de que temos informações) sofreram grande influência e até mesmo necessitavam permissão da própria

5 "Povos bárbaros - para os romanos, bárbaros eram os povos que habitavam fora das fronteiras do império e falavam outras línguas que não o latim, sua língua oficial” (COTRIN; FERNANDES, 2013, p. 237). 
Igreja para discutirem suas ideias, de modo que, é claro, sem o aval do papa e sem estar em defesa das concepções religiosas, não eram aceitas.

Foi neste contexto que dois grandes pensadores se destacaram, Santo Agostinho (354-430) e São Tomás de Aquino (1225-1274). Santo Agostinho entende a educação como a busca pela verdade, e com isso surge um grande problema, que não está relacionado ao universo, mas sim ao homem com ele mesmo (REALE; ANTISERI, 1990).

O homem é entendido como o grande mistério do mundo, e não mais o mundo. Entender o ser humano é algo extremamente complexo e até certo ponto impossível, exceto se Deus permitir que isso ocorra.

Devido a isso, para Santo Agostinho a Igreja desempenha desde o fim da Antiguidade um papel fundamental como educadora do povo, e não apenas com relação à inteligência, mas sim à formação humana e moral (LAUAND, 2013).

Por isso, para Agostinho, não é possível a verdade estar em busca de si mesma, é o homem que deve buscá-la, por isso a racionalidade não poderia auxiliar nesse processo, pois ele não ocorre no espaço sensível e sim se dá por meio da sensação da alma, pois o corpo é passivo e a alma que é ativa, ou seja, a revelação em busca do que Agostinho chama de teoria da iluminação se dá por meio de um ser superior à própria verdade; esse ser é Deus (REALE; ANTISERI, 1990).

Desse modo, para Santo Agostinho, de acordo com Cotrim e Parisi (1982, p. 158):

O objetivo educacional de Santo Agostinho era a salvação da alma. Embora não desvalorizasse os exercícios físicos, a literatura, a retórica, a lógica, a aritmética, todas estas matérias e atividades deveriam ser encaradas com um meio, cujo objetivo final deveria ser o aprimoramento da cultura religiosa.

É importante ressaltar que embora o objetivo educacional fosse a salvação da alma, outros fatores não eram dispensados, como retórica, literatura, lógica, aritmética, etc.; porém, a busca pela verdade que salvaria a alma se dava por meio de Deus.

Em seguida, São Tomás de Aquino acredita que não é possível descartar o pensamento racional, pois afirma que o mesmo não pode ser substituído pela teologia, e ao contrário de Agostinho, para provar a existência de Deus o conhecimento deve partir do próprio mundo (REALE; ANTISERI, 1990).

Por isso, a educação para ele deve encaminhar os seres humanos para o bem comum, favorecendo assim algumas virtudes, mas não é capaz de fazer com que o homem alcance o seu fim último, pois o mesmo é sobrenatural (REALE; ANTISERI, 1990). 
O desenvolvimento da educação, segundo Tomás de Aquino, depende mais do aluno do que o professor. O único e verdadeiro mestre é Deus, que através de sua infinita bondade nos criou portadores de uma razão que frequentemente nos ilumina. Santo Tomás de Aquino adota a concepção de Santo Agostinho dizendo que somente Deus é que nos ensina interiormente a verdade. O papel do professor durante as aulas pode ser comparado ao do agricultor diante das plantas. O agricultor não cria as plantas, mas as cultiva. Da mesma forma o professor não transmite a sabedoria; sua tarefa é preparar o terreno para que ela se desenvolva (COTRIM; PARISI, 1982, p. 162).

Assim, pois, percebe-se que embora a educação tenha uma função importante e ocorra por meio da razão natural, a qual permite às pessoas a distinguir o bem do mal, o ser humano só alcança o seu fim último seguindo a razão divina (REALE; ANTISERI, 1990).

Outro fator importante levantado por São Tomás de Aquino se refere ao descanso necessário, pois da mesma forma que o corpo precisa, a alma também, o que acaba sendo proporcionado pela brincadeira.

Desse modo:

Tomás recomendava o uso didático de brincadeiras e piadas para descanso dos ouvintes (ou alunos). E, tratando do relacionamento humano, Tomás chega a afirmar que ninguém aguenta, um dia sequer, ficar ao lado de uma pessoa aborrecida e desagradável (LAUNAND, 2013, p. 287-288).

Por fim, a educação na Média foi marcada por pressupostos teóricos voltados para os fundamentos do cristianismo, em que a verdade só poderia ser descoberta através da graça divina.

\section{Pressupostos teóricos da educação na idade moderna}

Avançando na história, a Idade Moderna é um período que inicia no ano de 1453, com o fim da Guerra dos Cem Anos, vencida pela realeza francesa, e termina no ano de 1789, com o início da Revolução Francesa (PEDRO; LIMA; CARVALHO, 2005).

Esse período foi marcado por uma política econômica mercantilista, onde a monarquia passou a ter o poder, desencadeando várias reformas e contrarreformas religiosas, surgindo também muitas correntes de ordem intelectual que tinham a finalidade de proporcionar respostas para as dúvidas dos homens e mulheres através do pensamento racional (PEDRO; LIMA; CARVALHO, 2005). 
Nesse contexto, um dos primeiros grandes pensadores desse período foi Erasmo de Rotterdam (1467-1536), que defendia uma ideia de educação mais centrada no próprio indivíduo, como sendo ele o responsável pela mesma. Isso, em grande parte, pela própria influência que recebera da Igreja, uma vez que fora sacerdote, e mesmo sendo dispensado dos votos em 1517, continuou exercendo o ofício ministerial (MORA, 2001).

Erasmo de Rotterdam defendeu a importância da leitura dos clássicos e o desenvolvimento integral do homem, ressaltando ainda que o homem pode moldar-se pela educação, ou seja, o ser humano pode escolher construir conhecimento e formar-se como ser integral. É uma opção de cada um. Por isso, a responsabilidade do fazer-se é responsabilidade de cada um. Não podemos transferir essa responsabilidade nem para a escola, nem para o Estado, nem para ninguém. É pessoal e individual. $\mathrm{Na}$ visão de Erasmo de Rotterdam, podemos buscar a perfeição por meio do conhecimento (SCHNEIDER, 2009, p. 88).

É interessante observar que Erasmo possui uma visão de educação onde o indivíduo passa a ser o responsável pela mesma, sem transferi-la à escola ou até mesmo ao Estado, o que parece ser muito comum na atualidade.

Dando continuidade, Michel de Montaigne (1533-1592) acredita que o pensar deve estar condicionado “[...] sobretudo em termos da descoberta da insignificância do homem que, ao avaliar-se equivocadamente superior às outras coisas, esquece-se dos vínculos que o unem à Natureza" (MORA, 2001, p. 2005).

Para mudar esse contexto, é necessário que desde cedo a criança conheça a filosofia, pois somente dessa forma passa a entender a necessidade de conhecer a prudência e a moderação, e com isso permitir que a criança possa criar e não somente repetir (SCHNEIDER, 2009).

A educação, nesse sentido, está associada diretamente à filosofia cuja premissa de Montaigne ressalta, onde a educação permitirá os homens serem bons ou maus, serem úteis ou inúteis, graças à instrução que possuem.

Dando continuidade, Jean-Jacques Rousseau (1712-1778), “[...] deixou importantes contribuições para o campo da política e da educação" (BAADE, 2013, p. 133). Embora o foco seja a educação, é importante mencionar a política também, porque ambas estão entrelaçadas para Rousseau.

Inicialmente, para Rousseau, é necessário distinguir governo de soberania, onde a soberania em uma sociedade democrática é pertencendo ao povo, ou seja, à coletividade; 
por isso, ela deve ser preservada em prol do interesse de todos, de modo que o contrato social $^{6}$ pressupõe o consentimento unânime em favor do coletivo (BAADE, 2013).

Para isso, a renúncia individual feita a favor da coletividade não seria a perda da liberdade, mas justamente o contrário, seria uma forma de assegurá-la à favor da vontade geral, que é o bom para todos; para isso, é preciso a ação ativa dos indivíduos (ARANHA; MARTINS, 2003).

Para Rousseau, a principal tarefa do mestre é a de ensinar a criança a viver e aprender o exercício da liberdade. Rousseau vê a criança como um ser puro, que deveria ser levada a tornar-se um ser integral, visando à busca da liberdade. O professor é, na visão de Rousseau, o condutor na busca da humanização (SCHNEIDER, 2009, p. 89).

Nestas condições, em que política e educação estão entrelaçadas, pois é por meio da política que se asseguram a liberdade e a vontade comum por meio de uma ação ativa dos indivíduos, tal ação somente é possível através da educação, que os humanizará.

\section{Pressupostos teóricos da educação na idade contemporânea}

Indo mais uma vez adiante na história, surge a Idade Contemporânea. A Idade Contemporânea inicia-se com a Revolução Francesa, em 1789, e se estende até a atualidade (PEDRO; LIMA; CARVALHO, 2005).

Esse período é marcado por um grande avanço no próprio modo de pensar, onde, a partir da Idade Moderna, ocorre a consolidação de diversos ramos das ciências, sobretudo as sociais (PEDRO; LIMA; CARVALHO, 2005).

Neste contexto, o modo de pensar a educação passa a atingir outros caminhos. Um deles se dá com Norbert Elias (1897-1990), que desenvolveu uma teoria a qual acentuava os aspectos da formação histórica dos fenômenos sociais, chamada de configurações sociais (TOMAZI, 2010).

Antes de explicar melhor a sua teoria, é importante procurar esclarecer outro conceito que está associado a ela. Elias procura desenvolver também o conceito de habitus, que mais tarde é novamente abordado por outros teóricos.

O habitus é o fator que indica os padrões de comportamento que são paulatinamente desenvolvidos, aceitos e também exigidos socialmente

${ }^{6}$ É uma espécie de acordo criado para formar a sociedade civil e estabelecer algumas leis que auxiliam na convivência (COTRIN; FERNANDES, 2013). 
para o convívio no interior das denominadas configurações sociais, que se expressam de forma decisiva na formação das imagens do eu e do nós e sobre a produção e a reprodução das identidades EU e Nós ao longo das gerações (SCHNEIDER, 2009, p. 92).

Para o autor, parece ficar claro que as pessoas desenvolvem relações através dos hábitos que se têm, e elas são aceitas no convívio dos indivíduos; essas relações é que são chamadas de configurações sociais.

Diante disso, a teoria de Elias possui uma grande abrangência, o que permite compreender a escola como uma estrutura que tem pessoas com personalidades individuais dentro de uma relação de interdependência, onde uma influencia a outra na maneira de pensar, sentir e agir, estabelecendo padrões comportamentais dentro do processo educativo (SCHNEIDER, 2009).

Em seguida, surge um grande teórico brasileiro, Paulo Freire (1921-1997), que acredita que a educação não deve tornar o homem e a mulher um objeto, pelo contrário, se a educação coisificá-los, os mesmos perdem a liberdade de agir (FREIRE, 1975).

Por isso mesmo a educação, para não instrumentar tendo como objeto um sujeito - ser concreto, que não somente está no mundo, mas também está com ele -, deve estabelecer uma relação dialética com o contexto da sociedade à qual se destina, quando se integra neste ambiente que, por sua vez, dá garantias especiais ao homem através de seu enraizamento nele (FREIRE, 2003, p. 61-62).

Assim, Freire vê a educação como uma relação dialética que deve levar as pessoas à uma reflexão da finalidade da sua própria existência, onde o encontrar-se no mundo e a ação delas nele pode transformá-lo.

Desse modo, “[...] assim como não há homem sem mundo, nem mundo sem homem, não pode haver reflexão e ação fora da relação homem-realidade" (FREIRE, 2003, p.17).

Essa relação implica a transformação do mundo, e é através das experiências que as pessoas têm com ele que podem transformá-lo ou deixá-lo como está, pois, muitas vezes, deixam de agir com uma atitude crítica, perdendo assim a possibilidade de ação (FREIRE, 2003).

A atitude crítica, portanto, se torna necessária para a humanização das pessoas, e ela só acontece através da educação dialógica e ativa dos envolvidos; em suma, é necessário estar aberto ao novo, não simplesmente porque é novo, e da mesma forma ao velho, mas sim para haver a transformação desejada (FREIRE, 1975). 
Contudo, convém esclarecer o que vem a ser o processo dialético; de acordo com Demerval Saviani, no prefácio que faz ao livro de Wachowicz (1989, p.7) “[...] é a concepção formal que implica uma correspondência direta e mecânica entre vários níveis de compreensão e intervenção da realidade [...]”.

Por fim, a relação existente entre as pessoas e o mundo implica diretamente na educação que se tem. Quanto mais aberta e dialógica, mais possibilidade de acerto e transformação, caso contrário, muitas vezes pode tornar o homem um ser coisificado.

Edgar Morin (1921) é outro importante teórico que faz várias reflexões sobre a educação na atualidade. Segundo Morin (2007), o saber científico em que a educação se apoia não deve apenas se situar na condição humana, pois a mesma é provisória; deve também se voltar para os mistérios do universo referentes à vida, ao nascimento do ser humano e até mesmo às opções filosóficos e crenças religiosas que se dão através das diferentes culturas.

A este propósito, Morin (2007) afirma que a educação deve se voltar para sete saberes que são necessários à educação do futuro $^{7}$, sendo eles: as cegueiras do conhecimento: o erro e a ilusão; os princípios do conhecimento pertinente; ensinar a condição humana; ensinar a identidade terrena; enfrentar as incertezas; ensinar a compreensão, e, por último, a ética do gênero humano.

Esses saberes são indispensáveis para que a educação do futuro mencionada por Morin cumpra o seu papel, por isso é muito discutida na atualidade por teóricos do mundo inteiro.

Outro teórico importante nesse período foi Michel Foucault (1926-1984); o sujeito é o tema chave de seu pensamento, pois por meio dele é possível “[...] analisar as diversas formas de sujeição a que nos vemos submetidos por meio de certos discursos e práticas, por meio de certas relações entre o saber e o poder" (MORA, 2001, p. 1136).

Ainda segundo Foucault, é nas instituições que se encontra a estrutura condicionante do poder, ou seja, as instituições, sejam elas quais forem, procuram fortalecer um vínculo condicionante de poder, estabelecendo uma hierarquia entre dominante e dominado (SCHNEIDER, 2009).

\footnotetext{
${ }^{7}$ Não temos nesse momento a pretensão de explicar os sete saberes necessários para a educação do futuro,
} uma vez que não é o nosso objetivo, mas, sim, mencionar a teoria de Morin sobre a educação. 
Nesse sentido, a própria escola nada mais é do que a reprodução de um determinado tipo de sociedade, onde predomina a ideia do dominante e se reproduz o melhor para ele.

Os condicionantes do modelo educacional em que a premiação se transfere totalmente para a atividade racional permitem que se desenvolva nas instituições educacionais uma perspectiva de aplauso para quem, por meio de sua capacidade intelectual, consegue reproduzir o modelo e as estruturas aí apresentadas. Faz-se necessário que olhemos com profunda atenção a supremacia da racionalidade nos modelos educacionais atualmente em vigência. Numa época em que podemos observar inúmeros debates enfatizando as inteligências múltiplas, é preciso que a instituição de ensino permita o desenvolvimento saudável das condições que permitirão a efetivação dessas "inteligências". A educação moderna apresenta atitudes de vigilância e adestramento do corpo e da mente humana, não visa às potencialidades, mas à manutenção do status quo (SCHNEIDER, 2009, p. 92).

Dentro desse contexto, para mudar esse panorama não se pode de forma alguma tornar o aluno um objeto, caso contrário se reproduzirá uma relação capitalista de reprodução entre dominante e dominado.

Por isso, é necessário identificar e desmistificar essa relação de dominação e poder, que muitas vezes pode estar escondida na linguagem utilizada no dia-a-dia (BAADE, 2013).

Pierre Bourdieu (1930-2002) teve uma contribuição marcante na interação entre cultura e educação. Tal autor formula três conceitos importantes nesse processo; são eles: habitus, campo e reprodução.

O conceito de habitus para Bourdieu (já mencionado por Norbert Elias) está relacionado a uma estrutura social que possui uma trajetória individual, e volta-se a uma relação estabelecida através da estratificação do poder entre o agente e a sociedade (MACHADO; AMORIM; BARROS, 2014).

Esclarecendo melhor:

O habitus pode, então, ser compreendido como um padrão social de sensibilidade e de comportamento que orienta a ação dos indivíduos. A conexão entre as posições objetivas, materiais e culturais, e suas práticas sociais não se dá com base na consciência do agente, mas sim pelo habitus da posição social interiorizada. Nesse sentido, o habitus é um conjunto de práticas sociais que é incorporado de forma inconsciente pelos indivíduos (MACHADO; AMORIM; BARROS, 2014, p. 193). 
É interessante observar que habitus para esse teórico está relacionado diretamente a uma reprodução de determinadas práticas sociais, que se dão de forma inconsciente e são dependentes do nível e posição social que o indivíduo ocupa na sociedade.

Por outro lado, o conceito de campos, para Bourdieu, é entendido como um espaço de luta constante, onde ocorre o desdobramento das relações sociais, levando em consideração os interesses específicos individuais e dos grupos (NERY, 2009).

Convém, no entanto, ainda deixar claro a ideia de Bourdieu referente ao terceiro conceito mencionado inicialmente, o de reprodução, pois sem ele não é possível compreender como o autor vê a educação.

Desse modo, ele entende o conceito de reprodução como sendo a própria “[...] dimensão social na qual se constituem as relações entre os atores sociais e as estruturas de poder, que se reproduzem, ou reproduzem o próprio sistema objetivo de dominação, o qual é interiorizado como subjetividade" (NERY, 2009, p. 130).

Fica claro que as relações de poder são determinantes na sociedade, e para Bourdieu elas estão relacionadas a três tipos de capital: simbólico, cultural e econômico (BAADE, 2013).

Capital simbólico: Ele diz respeito ao conhecimento que temos e que nos permite avaliar se algo é ou não importante em nossas vidas [...]. Capital cultural: Este capital é o conjunto de técnicas e habilidades necessárias para que se possa colocar em prática um plano de ação [...]. Capital econômico: Este por sua vez, não se refere exclusivamente às condições financeiras de que dispomos para concretizar o que desejamos, mas está relacionado às condições matérias de modo geral (BAADE, 2013, p. 180).

Diga-se de passagem, sempre que tomamos qualquer decisão em nossas vidas, levamos em consideração de forma inconsciente a importância que damos a esses três tipos de capital.

No entanto, esses tipos de capitais são regidos pelas relações de poder e dominação que legitimam hierarquias e divisões sociais, como exemplo, a própria instituição escolar, onde se reproduz bens simbólicos (MACHADO; AMORIM; BARROS, 2014).

Logo, Bourdieu vê a educação escolar de forma crítica. Para ele, a escola "[...] perpetua as desigualdades sociais, já que transmite aos estudantes a forma de conhecimento das classes dominantes utilizando-se de um discurso aparentemente neutro e oficial” (MACHADO; AMORIM; BARROS, 2014, p. 192). 
Por fim, é importante mencionar a ideia de educação de outro teórico com destaque na atualidade. Anthony Giddens (1938) possui um grande campo de interesse, e inicia sua discussão através das teorias clássicas, tentando reformular a teoria social contemporânea; para isso, reexamina a compreensão tida sobre o desenvolvimento e a modernidade, onde a tecnologia da informação tem um papel fundamental (TOMAZI, 2010).

Para o autor, a tecnologia da informação está sendo integrada aos processos educativos, o que de certa forma é preocupante, pois nem todos têm acesso a essa tecnologia; no entanto, é verídico que a escola não é mais a única fonte de transmissão do conhecimento e de saberes no mundo contemporâneo (NERY, 2009).

Giddens menciona ainda que a forma como as escolas e o próprio sistema de ensino estão organizados tende a manter as desigualdades de gênero. Ainda se mantêm regras que tendem a especificar o espaço do masculino e o espaço do feminino no contexto das instituições escolares. Igualmente, ainda se trabalham com textos que veiculam ideias estabelecidas acerca de gênero. Embora haja ainda a presença desses elementos, há, no que concerne ao desempenho escolar, uma maior eficiência das meninas com relação aos meninos. $\mathrm{O}$ fracasso escolar parece estar associado aos indivíduos do sexo masculino, na medida em que também problemas de ordem social são determinantes nesse caso, como o crime, o desemprego e a própria ausência de uma figura paterna (NERY, 2009, p. 139).

Desse modo, se torna notória a preocupação que Giddens tem com a educação. Parece ficar nítido que a educação está mais voltada aos próprios problemas sociais do que se possa imaginar inicialmente. Por isso, para entender a educação é necessário entender a própria estrutura social.

Outra preocupação de Giddens se refere à privatização do ensino que vem ocorrendo; isso de certo modo faz com que cada vez mais as instituições escolares acabem sendo o foco de interesses comerciais, e muitas vezes os próprios pressupostos do processo educativo acabam sofrendo alterações (NERY, 2009).

\section{Considerações finais}

Entender e analisar o processo evolutivo do pensamento racional e juntamente com isso o desenvolvimento da própria educação tem uma importância ímpar para entender o papel que a educação sempre desempenhou. 
A educação, dentro do ponto de vista formal, iniciou-se juntamente com o pensar racional. No decorrer da história ela foi sofrendo mudanças e se adaptando às necessidades dos homens e mulheres.

Na Idade Antiga, por exemplo, os pressupostos teóricos da educação desencadeiam um grande esforço para a superação do mundo real e transcendência à outra dimensão, cuja tarefa é a humanização, pois educar faz parte do processo humano.

Na Idade Média, se pode observar a forte influência que a Igreja exerceu no mundo, onde o seu modo de pensar prevaleceu e os pressupostos teóricos estavam voltados para uma educação religiosa.

Chegando à Idade Moderna, com as grandes mudanças ocorridas na forma de pensar e entender o próprio universo, mais uma vez os pressupostos teóricos da educação acompanham essa mudança de paradigma, onde a educação deveria estar mais centrada no indivíduo; no entanto, essa ideia muitas vezes foi mal interpretada, fazendo com que o próprio homem viesse a se achar superior às demais coisas existentes, até o momento que parece ter entendido a importância da coletividade.

Por último, temos a Idade Contemporânea, onde a discussão sobre a educação e os seus pressupostos ganhou ainda mais ênfase. A ideia de educação passou a atender cada vez de modo mais explícito (se é que isso é possível) os interesses pertencentes a quem está no poder; por isso, essa discussão ganhou muito importância.

Conforme mencionado desde o início deste artigo, talvez a educação e os seus pressupostos, por mais que na teoria pregassem a humanização e o pensamento crítico, na prática nunca tenham se desvinculado dos interesses de quem mandava; isso se observa muito bem em todo o decorrer da história, e se propaga até a atualidade.

Por isso, reflexões sobre essa temática contribuem de forma direta para uma possível análise e compreensão da educação e os pressupostos pelos quais ela se estruturou, levando em consideração a pretensão que sempre teve, pois, por mais que os teóricos de certa forma denunciem o que ela está fazendo, e sugiram um novo modelo, infelizmente parece que ela continua servindo apenas a quem está no poder.

\section{REFERÊNCIAS}

ARANHA, Maria Lúcia Arruda et al. Filosofando: introdução à filosofia. 3. ed. São Paulo: Moderna, 2003.

BAADE, Joel Haroldo. Filosofia: livro didático. Caçador: UNIARP, 2013. 
BENOIT, Hector. Sócrates: o nascimento da razão negativa. São Paulo: Moderna, 1996.

BRASIL (org.). Modelos filosóficos de educação. In: Universidade Luterana no Brasil (org.). Fundamentos da Educação. Curitiba: Editora Ibpex, 2009. Cap. 5, p. 81-93.

COTRIM, Gilberto.; FERNANDES, Mirna. Fundamentos da filosofia. 2. ed. São Paulo: Saraiva, 2013.

COTRIM, Gilberto.; PARISI; Mário. Fundamentos da educação: história e filosofia da educação. 6. ed. São Paulo: Saraiva, 1982.

FREIRE, Paulo. Educação como prática da liberdade. 5. ed. São Paulo: Paz e Terra, 1975.

FREIRE, Paulo. Educação e Mudança. 27. ed. São Paulo: Paz e Terra, 2003.

JAPIASSÚ, Hilton.; MARCONDES, Danilo. Dicionário Básico de Filosofia. 4.ed. Rio de Janeiro: Jorge Zahar, 2006.

LAUAND, Luiz Jean (org.). Cultura e educação na idade média. 2.ed. São Paulo: WMF Martins Fontes, 2013.

MACHADO, Igor José de Renó.; AMORIM, Henrique.; BARROS, Celso Rocha de. Sociologia hoje. São Paulo: Ática, 2014.

MORA, José Ferrater. Dicionário de Filosofia. Tomo II (E-J). São Paulo: Loyola, 2001.

MORA, José Ferrater. Dicionário de Filosofia. Tomo III (K-P). São Paulo: Loyola, 2001.

MORIN, Edgar. Os sete saberes necessários à educação do futuro. 12. ed. São Paulo: Cortez, 2007.

NERY, Maria Clara Ramos. Teorias contemporâneas que contribuem para pensarmos a educação. In: Universidade Luterana no Brasil (org.). Fundamentos da Educação. Curitiba: Editora Ibpex, 2009. Cap. 7, p. 119-141.

PEDRO, Antonio.; LIMA, Lizânias de Souza.; CARVALHO, Yone de. História do Mundo Ocidental. São Paulo: FTD, 2005.

REALE, Giovanni.; ANTISERI, Dario. História da Filosofia. Volume 1. 6. ed. São Paulo: Paulus, 1990.

SCHNEIDER, Laíno Alberto. O mito da caverna. In: UNIVERSIDADE LUTERANA NO BRASIL (org.). Fundamentos da educação. Curitiba: Editora Ibpex, 2009. Cap. 1, p. 1729.

SEARS, Kathleen. Tudo o que você precisa saber sobre mitologia: dos deuses e deusas aos monstros e mortais, seu guia sobre a mitologia antiga. Tradução, Leonardo Abramowicz. São Paulo: Gente, 2015. 
TEIXEIRA, Evilázio Francisco Borges. A educação do homem segundo Platão. São Paulo: Paulus, 1999.

TOMAZI, Nelson Dacio. Sociologia. 2. ed. São Paulo: Saraiva, 2010.

WACHOWICZ, Lílian Anna. O método dialógico na didática. Campinas: Papirus, 1989.

\section{Como referenciar este artigo}

REGERT, Rodrigo et al. Pressupostos teóricos da educação: algumas reflexões históricas. Revista Ibero-Americana de Estudos em Educação, Araraquara, v. 12, n. 3, p. 17561773, jul-set/2017. Disponível em: 〈http://dx.doi.org/10.21723/riaee.v12.n.3.2017.8542>. E-ISSN: 1982-5587.

Submetido em: 02/05/2016

Aprovação final em: 17/05/2017 